\title{
Understanding of a Novel Irradiation-induced Nanostructuring Process in SiC layer of TRISO fuel particles via Transmission Electron Microscopy
}

Subhashish Meher ${ }^{1}$, and Isabella J. van Rooyen ${ }^{2}$

${ }^{1}$ Materials Science and Engineering Department, Idaho National Laboratory, Idaho Falls, ID, 83415, USA.

${ }^{2}$ Fuel Design and Development Department, Idaho National Laboratory, Idaho Falls, ID, 83415, USA.

Certain metallic fission products are found to transport into and/or through the $\mathrm{SiC}$ layer of tristructural isotropic (TRISO) nuclear fuel particles, and various studies have been undertaken to understand this transport behavior [1, 2]. While the grain boundaries tend to be a pathway for fission product transport and, in some cases, trapping or precipitation in the form of multi-phased complex compounds, intragranular fission product precipitation has always been observed. Research on neutron irradiation damage tolerance of silicon carbide ( $\mathrm{SiC}$ ) and its composites, used in TRISO fuel and a candidate accident tolerant fuel cladding for light water reactors (LWR), has traditionally ignored the irradiationinduced "polymorphism" of SiC. In the post-irradiation advanced microscopy effort at Idaho National Laboratory, it has been recently discovered that the intragranular precipitation of fission products in the $\mathrm{SiC}$ layer of TRISO-coated fuels takes place via a dual-step nucleation mechanism that involves cubic $(\beta) \rightarrow$ hexagonal $(\alpha) \mathrm{SiC}$ polymorphic transition, and subsequent transition of $\alpha-\mathrm{SiC}$ into fission product precipitates, as shown in Figure 1 [3].

In this paper, the influence of the neutron irradiation induced damage structures on the extent of this precipitation has been studied using transmission electron microscopy. The analysis of damage structures (e.g., defect morphology and density) has been carried out to indicate the irradiation temperature and neutron fluence levels experienced by individual TRISO particles. The distinction of neutron irradiation damage structures as a function of the fuel kernel type, burn up level and fabrication properties of TRISO coated particles from the Advanced Gas reactor (AGR-1 and AGR-2) experiments has been examined and compared. Atomic scale structural and compositional analyses along with threedimensional electron tomography have been attempted using a FEI Thermis 200 with ChemiSTEM $^{\mathrm{TM}}$ capability. This approach has led to better understanding of the role of dislocations in Pd transport to the $\alpha-\mathrm{SiC}$ sites.

This discovery not only adds new fundamental understanding of physical behavior of polymorphic ceramics under irradiation, but also provides the following beneficial traits for non-fuel high temperature applications: 1) the extent of precipitation of the desired phase is directly dependent on the amount of precursor phase, the volume fraction of desired phase can be easily controlled by irradiation parameters. 2) Since precipitates are confined to the shape and size of the morphological template of the surrogate phase (as shown in Figure 1(c)), precipitate (e.g. Pd silicide) will remain stable in the SiC layer at high temperatures.

In conclusion, the present study reports a heterogeneous nucleation process in polymorphic $\mathrm{SiC}$ that challenges the conventional wisdom of precipitation in a nuclear reactor environment. The knowledge gained from irradiated fuel analysis could be applied to irradiation engineering for nanostructured SiC that can be useful for electronic or spintronic applications [4, 5]. 
References:

[1] E.J. Olivier, J.H. Neethling, Nuclear Engineering and Design, 244 (2012) 25-33.

[2] I.J. van Rooyen, T.M. Lillo, Y.Q. Wu, Journal of Nuclear Materials, 446 (2014) 178-186.

[3] S. Meher, I.J. van Rooyen, T.M. Lillo, Scientific Reports, 8 (1) (2018) 98.

[4] A.L. Falk et al., Nature Communications, 4 (2013) 1819.

[5] S. Castelletto et al., Nature Materials, 13 (2014) 151-156.

Acknowledgements: This work was sponsored by the U.S. Department of Energy, Office of Nuclear Energy, under U.S. Department of Energy Idaho Operations Office Contract DE-AC07-05ID14517, as part of the Advanced Reactor Technology Program. The United States Government retains and the publisher, by accepting the article for publication, acknowledges that the United States Government retains a nonexclusive, paid-up, irrevocable, world-wide license to publish or reproduce the published form of this manuscript, or allow others to do so, for United States Government purposes. The authors would like to acknowledge the efforts of Mr. James Madden in the focused ion beam fabrication of the transmission electron microscope samples, as well as other staff at the Materials and Fuels Complex at Idaho National Laboratory. Transmission electron microscopy work was carried out at the Center for Advanced Energy Studies-Microscopy and Characterization Suite.
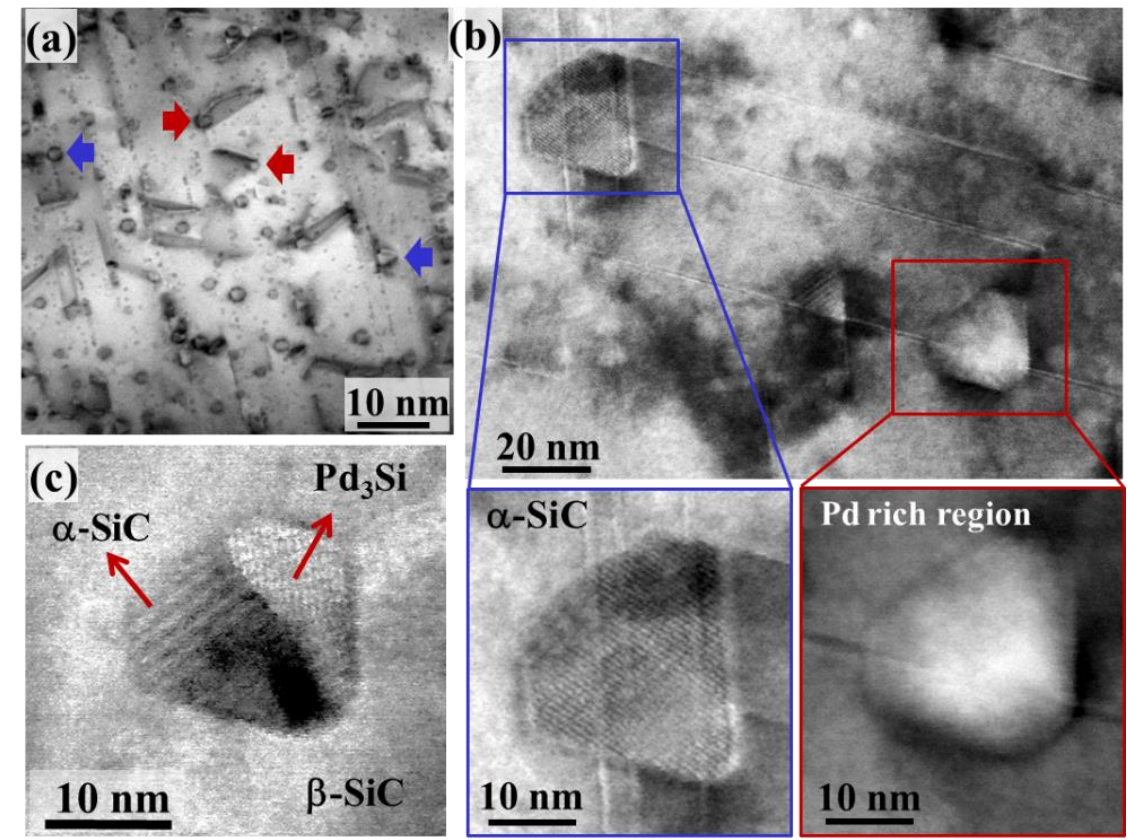

Figure 1: Neutron irradiation-induced microstructural changes in $\beta$-SiC layer of TRISO coated fuel particle [3]. a) A STEM micrograph of $\beta$-SiC along [110] zone axis, reveals Frank loops, stacking faults and damages induced from irradiation to a fast neutron fluence of $2.38 \times 10^{21} \mathrm{n} / \mathrm{m}^{2}$ in a temperature range of $1,000-1,200^{\circ} \mathrm{C}$. Red arrows indicate the precipitates at the ends of Frank loops. Blue arrows indicate precipitates along stacking faults. b) A STEM micrograph shows polygonal structures at structural defects with different chemical compositions. Energy dispersive spectrometry in TEM indicates a significant amount of $\mathrm{Pd}$, along with $\mathrm{Si}$ and $\mathrm{C}$, in the precipitate labelled by the red box. The precipitate labelled by the blue box contains only Si and C. c) A STEM micrograph along <110> of the $\beta$-SiC matrix clearly shows imprinting of $\mathrm{Pd}$ silicide into morphological templates of $\alpha$-SiC precipitates. Different crystallography and mass contrast within the hexagonal structure are clearly visible. 